\title{
Economía social como alternativa para el desarrollo socioeconómico en México
}

\section{Social economy as an alternative for socioeconomic development in Mexico.}

\author{
Eva Lozano Montero \\ monteroe@ugtomx.onmicrosoft.com \\ Benito Rodríguez Haros \\ benus27@yahoo.com
}

Universidad de Guanajuato

La economía social es resultado de las necesidades de equidad, de empleo y de financiamiento asequible tanto para los trabajadores como para las organizaciones, principalmente a las mipymes. Este estudio referencial con enfoque transversal analiza el impacto de la economía social y las diversas estrategias de este sector. Adicionalmente, se muestra su influencia en el desarrollo socioeconómico global, así como su contribución hacia una transformación sostenible; sin embargo, se requiere conciliar aspectos legales, de rendición de cuentas, de unificación conceptual y de liderazgo que consoliden a la economía social. Así, en este estudio, se proponen los fondos colectivos mutualistas como alternativa que coadyuve al desarrollo socioeconómico y a la competitividad empresarial.

Palabras clave: economía social, mipymes, fondo colectivo mutualista, tercer sector, México

The social economy is a result of the needs of equity, employment and affordable financing to both workers and organizations, mainly micro, small and medium-size enterprises (MSMEs). This referenced theoretical and transversal study analyzes the impact of the social economy and its different strategies. In adittion, the study shows their influence in the global socioeconomic development, as well as its contribution enhancing a sustainable transformation; however, it is necessary to comply with legal aspects, transparency, unification of concepts and leadership that helps to consolidate the social economy system. Thus, in this study, collective mutual funds are proposed as a supporting alternative for the enterprise socioeconomic development and competitiveness.

Key words: social economy, MSMEs, collective mutual funds, third sector, México 


\section{Introducción}

México no es la única nación en donde las mipymes enfrentan problemas de liquidez y los trabajadores carecen de un empleo digno y remunerado que refleje la disminución de la pobreza. Existen países que ya han pasado por crisis económicas, ante las cuales buscan las estrategias más viables y eficientes para la solución de las mismas, y la economía social (ES) surge como respuesta y esperanza a la generación de empleos, financiamiento, equidad en los sueldos y seguridad en el trabajo.

De acuerdo a la Encuesta Trimestral de Evaluación Coyuntural del Mercado Crediticio, durante el trimestre octubre-diciembre de 2017 los proveedores ocuparon el primer lugar como fuente de financiamiento para las empresas, con un $73.5 \%$; siguiéndole la banca comercial con 35.5\%. Asimismo, se señala que únicamente el $22.5 \%$ de las empresas utilizó nuevos créditos bancarios, indicando que encontraron condiciones más accesibles en términos de plazos y montos ofrecidos. No obstante, no se menciona la tasa de interés, ya que la siguen señalando como uno de los principales obstáculos para acceder a un crédito (41.1\%), conjuntamente con los montos exigidos como colateral (35.6\%) y las condiciones de acceso al crédito bancario (34.7\%) (Calva, 2018).

El liberalismo financiero fue induciendo las facilidades de intercambio entre las economías, así como la confianza extrema de sus operaciones y el nacimiento de alternativas de financiación innovadoras, lo que dio lugar a situaciones positivas y negativas. Los aspectos positivos incluyen tener amplia comunicación e interacción con otras entidades, incluyendo las extranjeras, lo que obliga a mejorar procesos y ser competitivos en los servicios que ofrecen. Entre los aspectos negativos se encuentra el alto riesgo de la financiación, derivada de una extrema confianza en los créditos y del ego de los directivos; además, el sistema capitalista está dominado por un grupo de oligopolios que controlan las decisiones relevantes en la economía global y que son los que financian las actividades de producción (Amin, 2018). Esto impulsa la búsqueda de opciones con énfasis en el pensamiento solidario, ya que en otras partes del mundo se han iniciado parecidas iniciativas con las que se pretende construir de un sistema económico alternativo.

A mediados del siglo XIX, en Francia se comienza a aplicar una combinación de principios teóricos provenientes de cuatro escuelas: la socialista, la social-reformista, la liberal y otra solidarista (Defourny, Develtere \& Fonteneau, 2002). Todo ello se desarrolla en un nivel de contradicción de actores sociales, en donde enarbolaron banderas tan disímiles como las del liberalismo, el socialismo y hasta el cristianismo. Fue un inicio en el que, con el tiempo, se fueron perfeccionando y definiendo los ideales de cada actor social.

En América Latina, la economía social, expresada por las mutualidades de trabajadores, surge a comienzos del siglo XIX y ya a finales de esa centuria se habían incorporado a las organizaciones cooperativas y a asociaciones de servicios comunitarios de una diversidad de productos y servicios. Así, durante el siglo XX ya existían innumerables prácticas de colaboración solidaria (Díaz, 2015).

Es así como emerge la economía social en todo el mundo, con distintas prácticas y diferentes conceptos, tratando de adaptarse a las necesidades de las entidades, entre las que destacan la participación colectiva, la cooperación, la autosuficiencia, la promoción 
del desarrollo humano, la democracia y la equidad de género, así como la conservación del equilibrio de los ecosistemas (Sánchez, García \& Rangel, 2007).

Con el lanzamiento de los Objetivos de Desarrollo Sostenible (ODS) por parte de las Naciones Unidas, las empresas deben integrar temas de capital humano, de conservación del medio ambiente y de desarrollo más que de crecimiento económico o enfocados en satisfacer deseos y necesidades, exacerbando la evolución del pensamiento de los empresarios, valorando las personas y el entorno. Esto, en consecuencia, se traducirá en la obtención de ganancias conjuntas, beneficiando a los colaboradores.

Por lo anterior, el objetivo de este trabajo de investigación es analizar el impacto socioeconómico evolutivo de la economía social en México, siendo este el fundamento para proponer la alternativa del fondo colectivo mutualista para las mipymes mexicanas.

\section{Revisión de la literatura}

La economía social tiene varias denominaciones: algunos países la nombran el tercer sector, economía solidaria, popular o economía del trabajo. En la actualidad, las empresas y organizaciones situadas en el tercer sector se están configurando como un polo de utilidad social en el sistema económico, llamando la atención a los políticos y científicos sociales. Las más conocidas son las cooperativas, las asociaciones, las mutuas y las fundaciones, las cuales se agrupan bajo la denominación de "economía social»(ES). Para referirse indistintamente a estas agrupaciones, se utilizan las denominaciones de economía social, de sector sin fines de lucro y de tercer sector. En consonancia con ello, diferentes autores han acuñado las siguientes acepciones: economía solidaria (Gaiger, 2007; Singer, 2007), economía solidaria y popular del trabajo (Cunca Bocayuva, 2007), socioeconomía solidaria (Melo, 2007), economía social y solidaria (Coraggio, 1998, 2004, 2005; Sabaté, 2007), economía popular (Quijano, 2007; Núñez, 2007), economía del trabajo (Coraggio, J. [org.]. (2007). La economía social desde la periferia. Contribuciones latinoamericanas. Buenos Aires: Altamira, UNGS.), economía de solidaridad (Razeto, 1999) y economía de la vida (Hinkelammert \& Duchrow, 2007).

El origen de la economía social se suele asociar con el asociacionismo obrero del siglo XIX. Frente a la degradación de las condiciones de vida, la explotación de los obreros, el desempleo y la migración a las ciudades que provocó la Revolución Industrial, los obreros se organizaron y surgieron las primeras cooperativas y sociedades mutualistas de la era moderna. En Estados Unidos fue Levitt (1973) uno de los primeros en utilizar la expresión «tercer sector», identificándolo con el sector no lucrativo y coincidiendo con la investigación de la Fundación Rockefeller sobre la importancia económica, social y política del mismo.

En ese contexto se propaga la economía solidaria, principalmente con las organizaciones no gubernamentales (ONG), bajo un principio de no lucro. Este término es empleado por el Sistema Nacional de Cuentas Integradas de las Naciones Unidas, que se centra en que las organizaciones que integran este organismo no persigan el objetivo de obtener ganancias, pero sí el del beneficio social (Sánchez et al., 2007).

Cabe indicar que las transformaciones socioeconómicas que se han presentado en la última década —el desempleo, la incertidumbre, las tensiones sociales y políticas, y la inseguridad-, así como la incapacidad de los Gobiernos para enfrentar tales situaciones, se ubican entre los principales elementos que pueden explicar la búsqueda de soluciones 
colectivas.

Por otro lado, la economía social también agrupa a aquellas entidades privadas, organizadas formalmente con autonomía de decisión y libertad de adhesión, que producen servicios de no mercado a favor de las familias y cuyos excedentes, si los hubiera, no pueden ser apropiados por los agentes económicos que las crean, controlan o financian (Chaves \& Monzón, 2008).

Asimismo, el Comité Económico y Social Europeo (CESE) dio a conocer un informe sobre la ES en la Unión Europea, proponiendo una definición de lo que esta comprende en conciliación con los criterios establecidos por el manual de la Comisión Europea (Barea \& Monzón, 2006) para la elaboración de cuentas satélite de las empresas parte de la ES. Dicha definición es la siguiente:

Conjunto de empresas privadas organizadas formalmente, con autonomía de decisión y libertad de adhesión, creadas para satisfacer las necesidades de sus socios a través del mercado, produciendo bienes y servicios, asegurando o financiando y en las que la eventual distribución entre los socios de beneficios o excedentes así como la toma de decisiones, no están ligados directamente con el capital o cotizaciones aportados por cada socio, correspondiendo un voto a cada uno de ellos (Monzón, Antuñano \& Marco, 2010, p. 25).

En varios países se observan los beneficios de la economía social. En España, la Confederación Empresarial Española de la Economía Social (Cepes) muestra resultados favorables para su población, pues sus empresas miembro contribuyen con un $10 \%$ del producto interno bruto (PIB) español y con el $12.5 \%$ del empleo, mientras que el $42.8 \%$ de la población está vinculada a la economía social. Además, en los últimos ocho años han surgido 29000 nuevas empresas y muchas empresas preexistentes se han transformado de empresas mercantiles a empresas de economía social. Por ello, no está de más indicar que las empresas que son parte de la economía social son organizaciones democráticas que valoran primordialmente a las personas y en las que los beneficios son distribuidos entre todos sus integrantes, lo que conlleva a que sean más competitivas.

En Latinoamérica también existen muestras de los beneficios que aporta la economía social. Así, en Argentina, donde las situaciones laborales aún son precarias, la economía social y solidaria (ESyS) se conoce como una economía alternativa y se le considera una respuesta a las injusticias que se cometen con los trabajadores.

Al mismo tiempo, una economía alternativa se entiende como una reorganización de las relaciones sociales en cuanto a la producción, distribución y consumo de productos, priorizando la conservación de la vida de todos sobre cualquier otra racionalidad. Las empresas recuperadas representan algunos de los casos de mayor éxito, siendo aquellas empresas que son abandonadas por los patrones o están en proceso de quiebra que han sido ocupadas por los trabajadores y puestas en marcha por los mismos. De esa forma, en el periodo comprendido entre los años 2001 y 2003 se recuperaron entre 127 y 180 empresas y entre 10000 a 12000 empleos (Abramovich \& Vázquez, 2007).

Como se mencionó anteriormente, la economía social tiene varias denominaciones, siendo la iniciativa para el surgimiento de otros movimientos, en los que cada país establece 
la legislación más conveniente sin olvidar el beneficio mutuo y el prevalecer del ser humano sobre el capital. Hoy en día, el tercer sector — que es otro término que se le asigna a la economía social - se desarrolla en países como España y México, por mencionar algunos; sin embargo, su confianza y credibilidad se ha visto mermada por inconvenientes, principalmente de rendición de cuentas.

El tercer sector representa a la sociedad civil organizada y es un término acuñado desde el campo de la economía. Se caracteriza porque agrupa un conjunto de actividades sociales que no se conducen con afán de lucro y no dependen ni del Estado ni del mercado para funcionar (Serna \& Monsiváis, 2009).

México, por ejemplo, ha experimentado cambios significativos que se observan en el desempeño del tercer sector de cara al terremoto de la Ciudad de México en 1985 y, en el año 2000, frente a la culminación de un Estado de partido hegemónico, que prevaleció por más de 70 años (Winder, 2004). En 2008, el Centro Mexicano para la Filantropía (Cemefi) estimó que existían más de 28750 organizaciones sin fines de lucro y 200 fundaciones en México, cifras que han cambiado con el tiempo para incrementarse a más de 40 086, como resultado de la más reciente demostración de acción social entre 2008 y 2010 (Inegi, 2012). Hasta hace 15 años, la información era escasa respecto al tercer sector puesto que en México no había investigación sobre el tema y el Gobierno carecía de elementos para constatar el alcance del mismo. En esa línea, se puede sostener que el pequeño tamaño del sector está enlazado con las relaciones de la Iglesia y el Gobierno, y con la falta de documentación de las actividades realizadas.

Al respecto del tercer sector, surgen las organizaciones híbridas definidas como aquellas que combinan la responsabilidad social de las empresas de dicho sector con la lógica comercial de las empresas tradicionales, buscando el equilibrio entre ambas ideologías. Cabe señalar que no es un modelo tan novedoso, ya que muchas empresas han implementado la responsabilidad social desde hace tiempo, buscando incentivar a los empleados al beneficiar a sus familiares, así como tener presencia en el entorno donde se desarrolla la organización.

De la misma manera, surgen las organizaciones B (benefit corporation), las cuales buscan resolver problemas sociales y ambientales a través de la fuerza del mercado (La Tercera, 2018). Lo anterior no significa que no generen ganancias, simplemente esa no es su meta primordial; es más, si la empresa se concentra en la sociedad y el medio amiente, la consecuencia es que se vuelven más competitivas, lo cual se refleja en mayor riqueza. Hay que añadir que las empresas B deben obtener una certificación que avale que su producción está enfocada en la responsabilidad social y ambiental.

Las benefit corporations son entidades legales que pueden nacer con las características requeridas para ser identificadas como empresas $\mathrm{B}$; asimismo, existen empresas operando que desean cambiar a la estructura legal de las empresas B, por lo que deben cumplir con las exigencias requeridas y modificar sus estatutos para ello.

La economía social comprende una responsabilidad social que también se ha modificado y adaptado a las iniciativas del mercado, surgiendo así la economía circular, que aboga por utilizar materiales biodegradables en la fabricación de bienes de consumo para que estos puedan volver a la naturaleza sin causar daños medioambientales al agotar su 
vida útil. De esa manera, se busca minimizar la producción de desechos vírgenes, cerrando los flujos económicos y ecológicos de los recursos (García, 2017).

Homer-Dixon menciona las tensiones que podrían provocar un colapso catastrófico del mundo, identificando las siguientes: las tasas de crecimiento poblacional desigual entre sociedades ricas y pobres; la creciente escasez de energía; los daños ambientales provocados por un uso indiscriminado de agua, tierra, recursos forestales y por la sobrepesca; la tensión climática con los cambios en la composición de la atmósfera; y la inestabilidad del sistema económico global con el progresivo aumento de la brecha de ricos y pobres (Homer-Dixon, 2009).

Sin embargo, se debería considerar que el daño más peligroso es la falta de consciencia del ser humano, que tiende a ser dominado por lo material y a olvidar los valores, lo que imposibilita la búsqueda de soluciones duraderas para enfrentar los problemas tanto sociales como ambientales. En otras palabras, la base de toda mejora se encuentra en la actitud y voluntad de los seres humanos, la cual ha sido olvidada por cuestiones materiales y de poder.

El Instituto Nacional de Economía Social (Inaes) define la economía social con la articulación de tres conceptos: actividad económica de organismos de propiedad social; relaciones de solidaridad, cooperación y reciprocidad; y conformación y administración asociativa. Estos conceptos conllevan a una forma diferente de hacer empresa $y$, en conjunto, proporcionan bienestar colectivo a los que participan a partir de su esfuerzo productivo, generando beneficios para la comunidad a la que pertenecen (Inaes, 2018).

Comparando esta definición con las anteriores, se aprecia cierta divergencia entre ellas, pues aunque persiguen el mismo objetivo y operan bajo similares valores y desde los principios de la economía social, cada estrategia y modelo de economía social se adapta a las necesidades de la región o país particular, exacerbando confusiones respecto a la conceptualización y objetivos establecidos.

La ES diferencia a las organizaciones de interés general, en las que los beneficiarios de las operaciones económicas son diferentes al grupo de personas que realizan las actividades, de las organizaciones de interés mutualístico, donde los beneficiarios de las operaciones económicas son el mismo grupo de personas que la controlan. Es decir, los beneficiarios no son un grupo de inversionistas capitalistas sino los socios, quienes son usuarios de la actividad y aportan un capital con la finalidad de utilizar los servicios de la organización, sin obtener rendimientos del capital invertido.

La historia económica mexicana se ha caracterizado por una inestabilidad intrínseca que ha afectado a los negocios y a las decisiones empresariales de diferentes formas. En ese sentido, los cambios que se han presentado han ocasionado la falta de permanencia de instituciones fundamentales para el desenvolvimiento en las empresas, su competitividad y el crecimiento de las mipymes. La liquidez en las empresas es imprescindible para alcanzar tasas de crecimiento económico sostenidas y se han realizado esfuerzos por impulsar a las mipymes; no obstante, su alcance no ha sido suficiente. Durante muchos años las mipymes han tratado de sobrevivir, pero la falta de liquidez, de aprendizaje organizacional y de cultura financiera las han obligado a crear su propia forma de aprendizaje y a adaptarse al entorno de manera empírica (Lozano, 2013a). 


\section{Fondo mutual social}

El mutualismo es otra expresión de la economía social, una forma colectiva de organización con objetivos comunes, los cuales no se pueden lograr individualmente, sino mediante el esfuerzo y los recursos de muchos. En la organización que resulta, le corresponde a cada socio en particular asumir responsabilidades y riesgos, siempre que contribuyan solidariamente a soportar los efectos positivos y negativos de la mutual.

Cuando se habla de mutualidad, se entiende la participación económica equitativa de los socios mediante un interés proporcionado a las aportaciones realizadas al fondo mutual. Si existen excedentes, se acuerda con anticipación en las cláusulas si serán parte de la capitalización o tendrán otros fines sociales. Además, el mutualismo, al ser coordinado como se fundó originalmente, desarrolla con el tiempo valores como la equidad, la honestidad, la ayuda mutua, la transparencia, la solidaridad y la igualdad de los socios, principalmente.

Las formas de organización social contempladas en México son: 1) ejidos; 2) comunidades; 3) organizaciones de trabajadores; 4) sociedades cooperativas; 5) empresas que pertenezcan mayoritaria o exclusivamente a los trabajadores; y 6) en general, todas las formas de organización social para la producción, distribución y consumo de bienes y servicios socialmente necesarios (Sedesol, 2014).

Así surge el concepto de fondo mutual social, que representa una protección entre los participantes en la que asumen voluntaria y mutuamente sus propios riesgos, existiendo un contrato del cual emana la obligación de contribuir económicamente y en la periodicidad estipulada. De esa manera, se obtiene el derecho de apoyo y auxilio en los términos estipulados.

Cabe indicar que la principal diferencia entre los fondos mutuales y las cooperativas es que las segundas tienen un aporte inicial, el cual es propiedad del asociado; mientras que en la mutual existen contribuciones, que son las cuotas, a las cuales se comprometen los asociados y que son pagadas al momento del ingreso $\mathrm{y}$, posteriormente, con una periodicidad mensual. Son estas contribuciones las que dan el derecho a recibir los servicios mutualistas.

En la Unión Europea, por su parte, las mutualidades de seguros francesas y alemanas son un caso de éxito en los que se han buscado soluciones jurídicas para asegurar el funcionamiento eficiente de las mutuales (lanniello, 2016). En España, a su vez, el mutualismo de previsión social — que forma parte del sistema de seguridad social— ha contribuido con sistemas complementarios privados centrados en brindar beneficios a la sociedad sin fines de lucro, así como en la reforma del sistema público de pensiones (De la Torre, 2003).

Otro caso de mutualismo se observa en Argentina. El Portal de Economía Solidaria menciona que en el país sudamericano se han formado más de 30000 cooperativas y mutuales, contribuyendo estas con cerca del 10\% del PIB. Además, estas mutuales proporcionan cada día productos y servicios a más de 14000000 personas, incluyendo servicios de salud, electrificación rural y medios de comunicación (Economía Solidaria, 2015). 


\section{Metodología}

En el presente estudio se analizan estrategias y modelos de otros países en torno a la economía social, su origen y su desarrollo como referencia para evaluar las contribuciones de la economía social y su evolución dentro del campo del desarrollo socioeconómico.

En el caso de México, este país ha padecido por varias décadas de la falta de modelos asequibles de financiación que contemplan sectores como los de las mipymes y startups, que reflejan el beneficio social y están orientados hacia la sostenibilidad.

Mediante un análisis deductivo de la literatura, y aplicando un enfoque transversal, se ha analizado el impacto y evolución de la economía social, determinando los principales retos a enfrentar, en específico para las mipymes de México —consideradas como áreas de oportunidad-. Para ello, se propone a los fondos colectivos mutualistas como alternativa de financiación, los cuales contribuirán al desarrollo socioeconómico en México. Además, se busca llamar la atención hacia la necesidad de realizar una discusión teórico-metodológica sobre la economía solidaria y sus efectos en otras organizaciones.

\section{Bases de la economía social en México}

La economía social se constituye como un marco de solidaridad, de ayuda mutua y de crecimiento social en el cual, al cumplirse los lineamientos y políticas establecidas, se potencia un verdadero cambio socioeconómico. Así, en 2002, México inició un camino integral respecto a la estructuración de la economía solidaria (EcoSol), implementando estrategias que inciden en una transformación de la sociedad económica. Con ese objetivo, se optó por construir mediante redes y cooperativas nacionales que integran tácticas para el beneficio del crecimiento social, esperando que se pudiera lograr un verdadero cambio económico (Sánchez et al., 2007).

La Ley de la Economía Social y Solidaria, basada en el artículo 25 de la Constitución Política de los Estados Unidos Mexicanos, establece en su artículo $3^{\circ}$ que el sector social de la economía es un sistema socioeconómico basado en relaciones de solidaridad, cooperación y reciprocidad, favoreciendo al trabajo y al ser humano, administrados de manera asociativa, con la finalidad de satisfacer las necesidades de sus integrantes y comunidades donde se desarrollan en concordancia con los términos que establece la presente Ley (Cámara de diputados del H. Congreso de la Unión, 2013). De la misma manera, los artículos 4 y 11 de la citada ley sustentan la constitución de alternativas estratégicas de economía social, contribuyendo al desarrollo económico.

Como resultado de la Ley de la Economía Social y Solidaria, se estructura el Compendio de Información Básica 2013-2017, que tiene como objetivo ofrecer información sobre el sector social de la economía. En su primera edición, de abril de 2018, se dan a conocer los avances que se presentan en ese aspecto en México y las cooperativas figuran como el tipo de entidad más desarrollada y destacada en la economía social, de lo cual son prueba las cooperativas que existen a nivel mundial (ver tabla 1). 
Tabla 1. Cooperativas en el mundo por región (2014)

\begin{tabular}{l|c|c|c}
\multicolumn{1}{c|}{ Regiones } & Cooperativas & Empleos & $\begin{array}{l}\text { \% de ingreso bruto } \\
\text { respecto al PIB }\end{array}$ \\
\hline África subsahariana & 85260 & 10914 & 0.08 \\
Asia & 1933299 & 5306521 & 0.13 \\
El Caribe & 1049 & 5248852 & 7.08 \\
Europa & 356380 & 816122 & 0.33 \\
Latinoamérica & 42765 & 37714 & 0.27 \\
Medio Oriente y norte de África & 162779 & 1675778 & 4.12 \\
Norteamérica & 31078 & 460278 & 3.46 \\
Oceanía & 1988 & $\mathbf{1 2 6 1 0 7 4 8}$ & $\mathbf{4 . 3 \%}$
\end{tabular}

Fuente: Inaes (2018).

Adicionalmente, el Inaes ha proporcionado apoyo a los rectores que demandan y requieren capacitación, recursos y atención, los cuales no fueron atendidos por otras instituciones debido a sus características particulares. Entre estas ayudas, se cuentan apoyos para el desarrollo de capacidades; apoyos para el desarrollo e implementación de proyectos productivos conformados por mujeres, jóvenes, hablantes de lenguas indígenas o personas con discapacidad; y apoyos para banca social y proyectos financiados con garantía líquida.

En marzo de 2015 se implementa el Observatorio del Sector Social de la Economía, cuya finalidad es difundir y sistematizar las experiencias de desarrollo y consolidación de actividades productivas, permitiendo el manejo de información de manera dinámica y accesible. Al momento, en América Latina existen solamente cuatro observatorios sobre economía social, ubicados en Argentina, México, Brasil y Perú.

Considerando la insuficiencia de financiamientos asequibles, principalmente para las mipymes y para los sectores económicos que no pueden acceder a los modelos tradicionales, y con fundamento en los modelos de financiación utilizados en otras entidades y los criterios internacionales, se explora una alternativa de financiación adaptable a las características de las organizaciones, logrando estructurar un modelo que coadyuve al desarrollo empresarial y social. Una propuesta de financiación asequible principalmente para las mipymes es aquella que posee un enfoque holístico y en la que se relacionan e integran aspectos administrativos, fiscales, legales, financieros y operativos que son necesarios en el funcionamiento de las mismas, de acuerdo a las necesidades particulares de cada sector, la cultura organizacional y otros aspectos relevantes en la conformación de la fuente de financiación.

Para que una alternativa de financiación sea accesible a los sectores no considerados por la banca comercial, principalmente, y en algunos casos por la banca de 
desarrollo, se determinan los factores a considerar para su estructuración: tasas de interés menores a las establecidas, motivando el pago; garantías acorde al riesgo de cada mipyme; requisitos necesarios para garantizar el crédito; énfasis en empresas de nueva creación o con antigüedad menor a un año, cumpliendo requisitos establecidos o mediante un mecanismo diferente; trabajo conjunto con la banca de desarrollo para garantizar el crédito; implementación de estrategias de asesoría y capacitación para las mipymes de cara al cumplimiento de créditos.

México y otros países enfrentan serios retos de desarrollo social y político, buscando maneras más innovadoras y eficientes de generar cambio; no obstante, el potencial de dichas iniciativas se ha desperdiciado al no existir un ambiente adecuado (políticas públicas, reconocimiento a la valoración de la sociedad por encima de los intereses propios, trabajo social mutuo, valoración al medio ambiente) para su pleno desarrollo.

\section{Propuesta de financiación de las mipymes en México basada en fondos colectivos}

Habiendo analizado los principios de la economía social, así como sus bondades y áreas de oportunidad, conjuntamente con los obstáculos al financiamiento detectados por estudios previos y los factores a considerar para estructurar una alternativa de financiamiento adaptable a las necesidades de las mipymes, se proponen los fondos colectivos mutualistas o fondos colectivos comunitarios, que es necesario diferenciar de los fondos mutualistas ya conocidos en el campo de las inversiones.

La escasez de financiamientos se observa en un estudio realizado por la World Business Environment Survey (Banco Mundial, 2000), aplicado a más de 10000 empresas de 80 países, considerando temas de política económica, regulaciones, impedimentos financieros y corrupción, entre otros. Los resultados obtenidos indican que el mundo considera los impuestos y las regulaciones como la primera restricción para el desarrollo de las empresas, la financiación como segunda restricción y la inestabilidad política como tercera restricción. Además, se observó que las grandes empresas recurren y confían en los bancos, mientras que las pequeñas empresas recurren a la familia y los amigos (Batra, Kaufmann \& Piedra, 2000).

A pesar de la gran diversidad de fuentes de financiación, aún existe un porcentaje considerable de mipymes que presentan dificultades para acceder a un crédito. Así, independientemente del tamaño de la empresa, entre el primer trimestre de 1998 y el cuarto trimestre del 2009, el porcentaje de empresas que se financia con proveedores pasó del $37.8 \%$ al $58.80 \%$, en tanto que el número de empresas que utiliza el crédito bancario pasó del $28 \%$ al $23.70 \%$. En paralelo, el número de empresas que se financia con banca de desarrollo pasó del $2.6 \%$ al $1.5 \%$, y se evidenció que el $82.80 \%$ de las empresas otorgan financiamiento, de las cuales el $78.50 \%$ lo destina a sus clientes con un periodo promedio de cobranza de 60 días (Banco de México, febrero de 2014).

Un estudio realizado con empresas del sector de la construcción en México muestra que tanto las mipymes como las startups tienen claras dificultades para acceder a un financiamiento, a menos que estén en contacto con la banca de desarrollo o que hayan participado en algún programa gubernamental de apoyo a las nuevas empresas . 
Asimismo, queda claro que, a través de la reforma financiera, se ha tratado de impulsar el financiamiento de las mipymes en beneficio del desarrollo económico, acompañándolo de capacitación por parte de la banca de desarrollo; de esa manera, se busca garantizar el eficiente aprovechamiento de los recursos, la capacidad de pago y, en consecuencia, la reducción de costos de financiamiento. Sin embargo, no se han reflejado los avances esperados, ya que en la banca comercial persiste el riesgo, lo que repercute sobre las tasas de interés. La reforma financiera va encaminada a ampliar la atención y el apoyo a las mipymes, promoviendo el desarrollo y la competitividad de las mismas; no obstante, existen aspectos importantes que se deben considerar, como el darle mayor certeza jurídica a la banca comercial, contemplar que los bancos tengan más poder para ejecutar sus garantías o el arraigo de radicación de personas. Además, se busca la manera de que los negocios informales se transformen en formales y para que se les pueda apoyar con financiamientos accesibles.

Los fondos colectivos mutualistas ofrecen un concepto diferente que está relacionado con la economía social y la responsabilidad social, buscando resarcir la necesidad de financiamiento. Estos se pueden considerar como una opción real y adaptable para el desarrollo de las organizaciones o la creación de las mismas; por ello, a continuación se mencionan algunos antecedentes y se define el concepto de fondo colectivo mutualista.

La constitución del fondo colectivo mutualista está basada en el artículo 25, párrafo séptimo, de la Constitución Política de los Estados Unidos Mexicanos, el cual declara que, bajo los criterios de equidad, productividad y sustentabilidad, se impulsará a las empresas del sector social y privado, de acuerdo a las modalidades que dicte el interés público en beneficio de los recursos productivos, cuidando el medio ambiente. Asimismo, menciona que la ley establecerá los mecanismos que faciliten la organización y la expansión de la actividad económica del sector social.

En lo relativo al aspecto fiscal, se propone que los fondos colectivos mutualistas se consideren dentro del Título III, artículo 79, fracción IX, de la Ley del Impuesto sobre la Renta LISR, vigente a 2018, el cual menciona que las sociedades mutualistas que no operen con terceros y que no realicen gastos para la adquisición de negocios deben considerarse personas morales con fines no lucrativos $y$, por lo tanto, no contribuyentes del impuesto sobre la renta. De esa forma, lo anterior coincide con los objetivos mencionados y los elementos considerados.

En lo referente a la tasa de aportación al fondo colectivo comunitario, como se ha mencionado anteriormente, el fondo colectivo mutualista no persigue el lucro; sin embargo, el apoyo se otorgará con una contribución porcentual a la cual se le denominará «tasa de aportación al fondo colectivo comunitario». Este término difiere de lo que se conceptúa como interés, ya que, de acuerdo al diccionario de la Real Academia Española, el interés es el "provecho, utilidad o ganancia», el "lucro producido por el capital», etc. Asimismo, de acuerdo al artículo 8 de la Ley del Impuesto sobre la Renta, "se consideran intereses, cualquiera que sea el nombre con que se les designe, a los rendimientos de créditos de cualquier clase [...]» (Cámara de diputados del H. Congreso de la Unión, 2018).

En el artículo 134 de la LISR se establece que se considera interés real el monto en el que los intereses exceden al ajuste por inflación (Cámara de diputados del 
H. Congreso de la Unión, 2018), que en la propuesta de financiamiento lo que se busca es solamente recuperar el efecto inflacionario, los gastos administrativos y el riesgo por incumplimiento de pago. Cabe señalar que, en caso de existir un excedente en la recuperación del financiamiento, este formará parte del fondo colectivo mutualista o comunitario, fortaleciéndolo.

De igual forma, la alternativa propuesta se sustenta en los Convenios Fiscales Internacionales y Fiscalidad de la Unión Europea 2011, Directiva 2003/48/CE, fechados el 3 de junio de 2003, en materia de fiscalidad de los rendimientos del ahorro en forma de pago de intereses (Diario Oficial de la Unión Europea, 2003), cuya aplicación definitiva fue hasta junio de 2005, como complemento a la Directiva 88/368/361, con variaciones relativas al concepto de pago de intereses. La Directiva de la Unión Europea define que la característica fundamental para considerar que existe interés se encuentra en que el título o contrato entrañe un riesgo única y exclusivamente sobre la remuneración por la cesión de capital, puesto que si el riesgo es asumido sobre el capital mismo, el instrumento generaría probablemente beneficios derivados de la participación en fondos propios (Carmona, Calderón, Martín \& Trapé, 2011).

La definición de intereses del artículo 6 de la Directiva señala que «[...] el sistema de intercambio de información/retención, no se aplica a los productos que tienen la forma de seguros o son operaciones de capitalización que generan rentas vitalicias o temporales o productos equivalentes a planes de pensiones [...]» (Diario Oficial de la Unión Europea, 2003). En la práctica, esto significa que, al estructurar una inversión generadora de intereses en un seguro (insurance-wrapper) o darle la formación de un instrumento generador de una pensión, se puede evitar estar dentro del ámbito de aplicación de la Directiva de la Unión Europea.

En esa línea, las disposiciones que se aplican debido a la Directiva de la Unión Europea comparten la idea que se desea aplicar en la propuesta de financiación, en donde existen aportaciones comunitarias colectivas que se consideran como no afectas a la aplicación de la Directiva, que en este caso serían no afectas a las disposiciones de la Ley del Impuesto sobre la Renta.

Por lo anterior, en la propuesta del fondo colectivo mutual se constituye una tasa de aportación colectiva comunitaria menor a la de la banca comercial, considerando los factores de inflación, riesgo por incumplimiento y gastos operativos, en donde no se pierde la misión de la propuesta de financiación, que es el desarrollo de las mipymes y su repercusión en el bien social. Así, se entiende que se aplicará esta tasa sobre el excedente del préstamo solicitado respecto al monto aportado y que cualquier remanente será acumulativo al fondo colectivo; y, además, se les proporcionará la capacitación necesaria para garantizar el pago oportuno del crédito. Lo que se busca es conservar el poder adquisitivo del dinero que se presta y absorber el riesgo por el crédito, el cual se estima que sea mínimo debido a que los prestatarios forman parte del fondo y el crédito otorgado es parte de sus aportaciones.

Por último, vale resaltar que el fondo colectivo mutual está pensado para los sectores que no son atendidos por la banca comercial y que son de gran relevancia para el desarrollo socioeconómico del país, como los de las mipymes y las startups, especialmente cuando habitan un entorno sostenible. 


\section{Conclusiones}

La economía social ha sido sin duda un movimiento en beneficio de los sectores más desprotegidos, buscando opciones innovadoras que apoyen a la sociedad y al medio ambiente. Cada vez se requiere de mayor énfasis en los valores, la valoración del ser humano y la naturaleza, temas para los que la evolución de la economía social demuestra grandes avances, fortaleciendo la sustentabilidad del sector económico.

Los avances tecnológicos impulsan el capital hacia una competencia global, ya que se centran en la productividad y las ganancias de manera acelerada sin considerar el tiempo que requiere la naturaleza para restablecer los recursos utilizados y llegar a un equilibrio. Además, con el modelo económico actual, la dimensión del avance en el desarrollo tecnológico no es equivalente a la generación neta de empleos, lo que provoca un desequilibrio económico social.

Los valores son de gran relevancia en la economía social al estar fundada esta en la confianza y el apoyo mutuo. En contraste, existen muchas organizaciones con legitimidad deficiente y que conciben aspectos básicos de su funcionamiento sin abundar en situaciones de transparencia, de responsabilidad social y de efectos jurídicos. Acaso por ello, la confianza social resulta tan frágil y sensible a la percepción, siendo dependiente de la opinión que se tenga respecto de las actividades de economía social implementadas en tanto es muy difícil de conseguir y, al mismo tiempo, muy fácil de perder.

Las mipymes, que son de vital importancia para el desarrollo económico de México, se han visto privadas por varios años de uno de los principales motores para su desarrollo: el financiamiento. Se puede sostener, entonces, que la banca múltiple se ha dedicado a prestar dinero a las grandes empresas y al crédito para el consumo dirigido al público en general, que destina sus recursos a la adquisición de bienes y servicios; y se ha olvidado de los proyectos productivos generadores de empleos de las pequeñas empresas.

En ese contexto, las empresas que han permanecido en el mercado lo hicieron con el crédito concedido por los proveedores o por algún familiar o amigo del empresario, dejando como última opción el apalancamiento con la banca comercial debido, principalmente, a los requerimientos solicitados y al costo del financiamiento.

La banca de desarrollo, en diálogo con lo establecido en la reforma financiera, se ve obligada a buscar nuevas estrategias que coadyuven a la competitividad, principalmente de las mipymes. Para ello, exhorta a instituciones como el Banco de México, la Comisión Nacional Bancaria y de Valores y el Banco de Comercio Exterior a realizar diversos estudios respecto a factores que han inhibido la eficiente aplicación de la reforma financiera, aportando así acciones en conjunto que contribuyan al logro de los objetivos planteados.

La economía social, conjuntamente con todas las estrategias y modelos que han surgido de este movimiento, requiere del respaldo necesario para su operatividad y trascendencia en los sectores económicos, siendo las siguientes algunas consideraciones útiles para su fortalecimiento:

1. Unificar criterios y conceptos para lograr la propia identidad de la economía social, además de una mejor interrelación entre los sectores económicos, coadyuvando a la competitividad. 
2. Establecer un verdadero liderazgo de la economía social que permita visualizar los beneficios de las organizaciones y considere las particularidades de cada sector económico.

3. Conformar legalmente los lineamientos de la economía social, considerando la flexibilidad requerida para cada ámbito económico.

4. Lograr la participación de los Gobiernos, la sociedad y las universidades para que trabajen de manera coordinada y se unifiquen los criterios de operatividad.

5. Fortalecer apoyos para la sostenibilidad de las operaciones productivas empresariales, principalmente las más desprotegidas.

La propuesta de los fondos colectivos mutualistas es una respuesta a las necesidades de liquidez, por lo que su funcionamiento adecuado depende de la flexibilidad y adaptabilidad a las particularidades de cada sector económico, siendo recomendables las agrupaciones por actividad industrial en tanto coadyuvan al fortalecimiento de las estrategias y objetivos del Inaes.

No está de más indicar que esta investigación abre un espacio a futuros estudios para seguir analizando la evolución de la economía social y sus imperfecciones, aportando ideas que impacten positivamente sobre las necesidades de financiamientos y equidad social, y en simultáneo sobre la sociedad y la naturaleza.

Finalmente, se hace evidente la necesidad de realizar más trabajos de investigación por región o por actividad preponderante, atendiendo directamente a los mecanismos de financiamiento, así como de darlos a conocer a las diferentes instancias de interés, como las cámaras de las empresas y las asociaciones de profesionistas, para que difundan los contenidos entre los empresarios de las mipymes. Asimismo, se hace preciso documentar las experiencias adquiridas por las empresas, por sector productivo, al formar parte de alguna actividad de la economía social o al solicitar un crédito, lo cual servirá a otras empresas para evitar aspectos negativos, reduciendo costos e impulsando el desarrollo de las mipymes.

México se encuentra hoy en día limitado por una cultura política y económica favorecedora de la economía social, pero que aún presenta riesgos en la operatividad de algunas de sus estrategias. Por esa razón, resulta necesario establecer políticas de transparencia y evitar caer en el capitalismo. 


\section{bibliografía}

\author{
Abramovich, A., \& Vázquez, G. \\ 2007 \\ Experiencias de la Economía Social \\ y Solidaria en la Argentina. Estudios \\ Fronterizos, 8(15).
}

\section{Amin, $\mathbf{S}$.}

2018

¿Debacle financiera, crisis sistémica?

Herramienta Revista de Debate y

Crítica Marxista. Recuperado de: www.

observatoriocrisis.com

\section{Banco Mundial.}

2000

World Business Environment Survey

(WBES). Recuperado de: http://info.

worlsbank.org/governance/wbes/

Barea, J., \& Monzón, J. L.

2006

Manual para la elaboración de las cuentas satélite de las empresas de la economía social: cooperativas y mutuas. Comisión

Europea.

\section{Batra, G., Kaufmann, D., \&}

Stone, A.

Investment Climate Around the World.

Voices of the Firms from the WBES. Banco Mundial.

\section{Calva, J.}

Instituciones de Crédito y Financiamiento

del Desarrollo (vol. 6). México: Consejo

Nacional de Universitarios.

\section{Cámara de diputados del $\mathbf{H}$.}

\section{Congreso de la Unión}

Ley de la Economía Social y Solidaria. DOF

11-06-2013. Recuperado de: https://www. gob.mx/inaes

\section{Cámara de diputados del H.}

\section{Congreso de la Unión.}

2018

Ley del Impuesto sobre la Renta.

Secretaría General. Secretaría de

Servicios Parlamentarios, última reforma

Recuperado de: https://www.oas.org/

juridico/spanish/mesicic3_mex_anexo13.

pdf

Carmona, N., Calderón, J. M., Martín, A., \& Trapé, M.

2011

Convenios Fiscales Internacionales

y Fiscalidad de la Unión Europea.

Conferencia Interamericana de Seguridad Social.

Chaves, R., \& Monzón, J. L.

The Social Economy in the European

Union, European Economic and Social

Committee. Bruselas: EESC, CIRIEC.

\section{Comisión Nacional para la}

Protección y Defensa de

los Usuarios de Servicios

Financieros [CONDUSEF].

2014

Reformas.gob.mx. Recuperado de: www. diputados.gob.mx

\section{Coraggio, J.}

1998

Economía popular urbana: una nueva perspectiva para el desarrollo local (cartilla 1). Buenos Aires: Programa de Desarrollo Local, Instituto del Conurbano, Universidad Nacional de General Sarmiento.

\section{Coraggio, J.}

Una alternativa socioeconómica necesaria: la economía social. En Política social y economías social: debates fundamentales. Buenos Aires: Altamira, UNGS-OSDE. 


\section{bibliografía}

\section{Coraggio, J.}

2005

¿Es posible otra economía sin (otra)

política? Ponencia presentada en el

panel Cuestión social y políticas sociales:

¿políticas de emergencia o construcción

de políticas estratégicas de carácter

socioeconómico? II Congreso Nacional de

Sociología, VI Jornadas de Sociología de la UBA, Pre ALAS, Buenos Aires.

\section{Cunca Bocayuva, P.}

2007 Economía solidaria y la nueva centralidad del trabajo asociado. En J. L. Coraggio (org.), La economía social desde la periferia. Contribuciones latinoamericanas. Buenos Aires: Altamira, UNGS.

\section{De la Torre, $P$.}

2003 El mutualismo de previsión social. Revista de Economía Pública, Social y Cooperativa, (47), 59-68.

Defourny, J., Develtere, P., \& Fonteneau, B.

2002 La economía social en el Norte y en el Sur. Buenos Aires: Corregidor.

\section{Diario Oficial de la Unión}

\section{Europea.}

DO L 157/38. Directiva 2003/48/CE del

Consejo en materia de fiscalidad de los rendimientos del ahorro en forma de pago de intereses. Recuperado de: https://www. boe.es/doue/2003/157/L00038-00048.pdf

\section{Díaz, J.}

2015 Economías solidarias en América Latina. Guadalajara: Instituto Tecnológico y de Estudios Superiores de Occidente.

\section{Donzelot, J.}

2007

La invención de lo social. Ensayo sobre la declinación de las pasiones políticas. Buenos Aires: Nueva Visión.

\section{Economía Solidaria.}

2015

Economía solidaria, necesaria para potenciar el desarrollo social de México: Senado. Recuperado de: https://www. economiasolidaria.org

\section{Fondo Monetario Internacional.}

Estadísticas financieras internacionales $y$ archivos de datos y estimaciones del PIB del Banco Mundial y la OCDE. Recuperado de: https://datos. bancomundial.org/indicador/FM.LBL.

BMNY.GD.ZS?view=chart

\section{Gaiger, I.}

La economía solidaria y el capitalismo en la perspectiva de las transiciones históricas. En J. L. Coraggio (org.), La economía social desde la periferia. Contribuciones latinoamericanas. Buenos Aires: Altamira, UNGS

\section{García, L.}

Economía circular y su papel en el diseño e innovación sustentable. UNIMAR.

Recuperado de: http://ojseditorialumariana. com/index.php/libroseditorialunimar/

\section{Hinkelammert, F., \& Duchrow, U.}

Un mundo diferente es posible. La reestructuración del régimen de propiedad desde abajo, en la perspectiva de la vida y del bien común. En J. L. Coraggio (org.), La economía social desde la periferia.

Contribuciones latinoamericanas. Buenos Aires: Altamira, UNGS 


\section{bibliografía}

\section{Homer-Dixon, T.}

2006

The Upside of Down: Catastrophe,

Creativity, and the Renewal of Civilization.

Washington D. C.: Island Press.

\section{Homer-Dixon, T.}

2009

Our panarchic future: Complexity and collapse. World Watch, 22(2), 9-15.

Recuperado de: http://www.worldwatch.

org/files/pdf/March-April.pdf

\section{lanniello, F.}

2016

La mutua europea: el reto de un nuevo renacimiento del mutualismo. Comisión Europea.

\section{Instituto Nacional de} Estadística y Geografía [Inegi].

Cuentas satélite de instituciones sin fines de lucro, Serie 2008-2010. México.

\section{La Tercera.}

Empresas B. Crecimiento, sustentabilidad y buenas prácticas. Recuperado de: https:// sistemab.org> uploads>2018/11 > ediciónespecial-la-tercera

\section{Levitt, T.}

1973 The Third Sector-New Tactics for a Responsive Society. Nueva York: Division of American Management Association.

\section{Lozano, E.}

Percepción de las MiPyMEs constructoras acerca de los apalancamientos financieros: el estado de Guanajuato como estudio de caso. En XVIII Congreso Internacional de Contaduría, Administración e Informática (cap. II, pp. 1-27). México, D. F.: Universidad Nacional Autónoma de México.

\section{Lozano, E.}

2013b Alternativas de financiamiento para el desarrollo regional del sector de la construcción en el estado de Guanajuato. Tercer Congreso Internacional sobre la MiPyME. Celaya, Gto. Setiembre.

\section{Melo, A.}

2007

Economía solidaria: una reflexión a la luz de la ética cristiana. En J. L. Coraggio (org.), La economía social desde la periferia. Contribuciones latinoamericanas. Buenos Aires: Altamira, UNGS.

\section{Mendoza, V.}

2012

Los ocho obstáculos de los créditos PyME. Revista 30 promesas: El talento que transformará a México, (1162).

\section{Banco de México}

febrero Encuesta Trimestral de Evaluación

de 2014 Coyuntural del Mercado Crediticio.

Recuperado de: https://www.banxico.org.mx/

\section{Monzón, J. L.}

1987 La economía social en España. Revista de Economía Pública, Social y Cooperativa,

(0), 19-29. Recuperado de: http://ciriecrevistaeconomia.es/banco/03

Monzón, J., Antuñano, I., \& Marco, F.

2010 Economía social. Sectores de la nueva economía $20+20$. CIRIEC. Universitat id Valencia.

\section{Núñez, 0.}

2007
La economía popular, asociativa y autogestionaria. En J. L. Coraggio (org.), La economía social desde la periferia. Contribuciones latinoamericanas. Buenos Aires: Altamira, UNGS. 


\section{bibliografía}

\section{Quijano, A.}

2007

¿Sistemas alternativos de producción?

En J. L. Coraggio (org.), La economía

social desde la periferia. Contribuciones

latinoamericanas. Buenos Aires: Altamira,

UNGS.

\section{Razeto, L.}

1999

Economía de la solidaridad. Concepto,

realidad y proyecto. Recuperado de:

http://www.luisrazeto.net/content/

la-econom\% c3\%ada-solidaria-concepto-

realidad-y-proyecto

\section{Sabaté, F.}

¿Es posible otra economía? El caso de las asambleas vecinales y la recuperación de empresas en la Argentina reciente. En J. L. Coraggio (org.), La economía social desde la periferia. Contribuciones latinoamericanas. Buenos Aires: Altamira, UNGS.

\section{Sajardo Moreno, A., \& Chaves, R.}

Balance y tendencia en la investigación sobre Tercer Sector no lucrativo. Especial referencia al caso español. Revista de Economía Pública, Social y Cooperativa, (56), 87-116. Recuperado de: https://www. researchgate.net/publication/5004274_ Balance_y_tendencias_en_la_ investigacion_sobre_Tercer_Sector_no_ lucrativo_Especial_referencia_al_caso_ espanol

Sánchez, M. G., García, G., \& Rangel, $\mathbf{T}$.

como alternativa de desarrollo

socioeconómico en México. Hidalgo,

México: Universidad Tecnológica de Tula

Tepeji.

\section{Secretaría de Desarrollo Social [Sedesol].}

2014

\section{$A B C$ de la Economía Social e Inaes.}

Recuperado de: https://www.gob.mx/cms/ uploads/attachment/file/102028/ABC_de_ la_Econom_a_Social_e_INAES.pdf

\section{Serna, G., \& Monsiváis, A.}

2009

El tercer sector en México: perspectivas de investigación. México: CEMEFI, Instituto Mora.

\section{Singer, P.}

2007 Economía solidaria. Un modo de producción y distribución. En J. L. Coraggio (org.), La economía social desde la periferia. Contribuciones latinoamericanas. Buenos Aires: Altamira, UNGS

\section{Winder, D.}

Innovations in Strategic Philanthropy. The Case of Mexico. Nueva York: Synergos Institute.

Fecha de recepción: 06 de julio de 2018 Fecha de aceptación: 10 de enero de 2019 